\title{
LAUDATIO ON THE OCCASION OF THE INVESTITURE OF PROFESSOR JOHN DENIS SARGAN WITH THE DEGREE OF DOCTOR HONORIS CAUSA OF THE UNIVERSIDAD CARLOS III, 2 February 1993
}

\author{
ANTONI ESPASA
}

It is a challenging task to review the research carried out by Professor Sargan which has covered such a broad range of areas and which offers general and unifying approaches to tackling problems and to obtaining results.

Denis Sargan started his undergraduate education in 1941 at St. John's College in Cambridge. In two years he completed his B.A. degree in Mathematics. At the time the more interesting mathematicians were occupied by war duties, and Professor Neumann left Cambridge after Denis Sargan had completed his first year there.

This atmosphere of the Second World War meant that Denis Sargan, who would have probably gone into Theoretical Physics, didn't have any specific plans about his professional future. He was drafted into a junior scientific officership in the Ministry of Science. There he was attached to the Air Force, where he was concerned with the interpretation of tests for new weapons. However, as he recalls, his tasks would only require an elementary statistical knowledge: computation of standard deviations and running some regressions.

In an interview with Peter Phillips published in 1985 in Econometric Theory, Sargan points out that after his first general reading in Economics, he considered Economics a "dismal science." He got into Economics after reading Keynes' "General Theory," which interested him in the possibility of applying mathematics to economics. Then, when he returned to Cambridge in 1946 he

I can only apologize for my audacity in accepting to deliver this laudatio. In order to remedy the limitation of my resources, I have benefited from Manuel Arellano's help and I have used the papers by David Hendry and Ken Wallis (1984), Peter Phillips (1985), and Esfandiar Maasoumi (1988a, 1988b). These papers review and summarize the works of the common master, who is considered to be one of the major contributors to Econometrics; in the words of Professor T.W. Anderson: "one of the most distinguished econometricians of our generation." I am grateful to Peter Phillips and Grayham Mizon for their comments in preparing the English version of this laudatio. Address correspondence to: Antoni Espasa, Departamento de Estadistica y Econometrica, Universidad Carlos III, 28903 Getafe (Madrid), Spain. 
completed an M.A. and a second B.A. in Economics. During these studies he attended Bartlett's lectures on Time Series and made contact with the Department of Applied Mathematics. However, in these two years he focused his studies on economics and game theory after reading the book by John von Neumann and Oskar Morgenstern.

His appointment, in 1948, as lecturer in Economics at the University of Leeds started his first research period, which continued until 1958 when he visited some universities in the USA. During his stay at Leeds, Sargan began to produce his great contributions to econometrics despite being equally dedicated at that time to mathematical economics.

Products of his research in economic theory are his papers "A New Approach to the General Distribution Problem," "An Illustration of Duopoly," "Subjective Probability and the Economist," "The Period of Production," "The Distribution of Wealth," and "The Instability of the Leontief Dynamic Model." This interest in economic theory will have a great influence on Sargan's later econometric work, as Maasoumi (1988b) points out. The appreciation and profound knowledge that Sargan displays in those works about the dynamic processes in economics lead him to statistical modelling and to the development of empirical models of the economy. These models, as we will see, have combined crucial advances in econometric methodology with contributions to the economic debate in areas like inflation in prices and wages and the Phillips curve. As Hendry and Wallis (1984) point out, Sargan has been a pioneer in integrating economic theory into empirical models. At the same time, he developed an interest in simultaneous equation models in accord with the idea that the estimation of models representing economic systems would improve policy design.

This central motivation in the application of statistics to economic analysis has always given Denis Sargan's econometric work a distinctive operational flavour (Hendry and Wallis, 1984). Thus, if the statistical formulation of a problem would require a new estimator, the latter would be developed and its statistical properties analyzed, and statistical tests would be conducted; finally, all this would be implemented in computer code allowing for its application by empirical researchers.

Professor Sargan's research work is characterized by its broadness, depth and completeness. He is a scientist that has been able to recognize the important problems and has aimed his efforts at obtaining general results. For this reason, he has never been concerned with quickness in the publication of his work. Instead, he has been interested in accomplishing atemporal contributions. An illustrative example is his paper "An Approximate Distribution of the TwoStage Least Squares Estimators," which he delivered at the 1963 Econometric Society European Meeting in Copenhagen, an abstract of which appeared in Econometrica in 1964. This work shows how soon Sargan became engaged in obtaining better approximations for econometric estimators than simple asymptotics would provide, for which he uses the Edgeworth expansion. However, 
Sargan preferred to expand this work and he continued research on it until its ultimate publication in 1971 .

This integral view of research has meant that many working papers were never submitted for publication to a professional journal, despite their important contributions. The two volumes in which E. Maasoumi collects Sargan's most important contributions, published in 1988, contain twenty-five papers, six of which were previously unpublished although these papers, distributed as working papers and conference papers, had a fundamental influence on econometrics. This has also been one of the main lessons that Denis Sargan has transmitted to his students, who learned that theses were not finished when some results were achieved but only when a planned research sequence was completed.

In his Leeds years, Sargan was impressed by the work of Jan Tinbergen for the League of Nations and he was interested in building a Klein I-type model for the United Kingdom. But the problem he faced was, in his own words, inadequate data. At that stage he became interested in methods of estimation and very soon considered the method of instrumental variables as a general approach to the problem. The method of instrumental variables dated back to the work of Wright (1928) and Reiersol $(1941,1945)$ and had been applied and developed independently by Geary (1949). With the publication of the work done in the Cowles Commission on LIML estimators by Anderson and Rubin (1949, 1950), Sargan perceived the proximity of both methods and generalized the estimation procedure using instrumental variables to the case where the number of instruments exceeds the number of parameters. The task was completed in two papers, one appearing in 1958 in Econometrica, and the other a year later in the Journal of the Royal Statistical Society. As well as the work of Anderson and Rubin, in 1950 there appeared the first of the famous Cowles Commission monographs in econometrics (edited by Koopmans, 1950), which Sargan immediately recognized as important and described as a pioneering work "that moved the whole thing on from where it had been earlier." This monograph, number 10, and later, number 14 edited by Hood and Koopmans (1953), studied primarily econometric models of simultaneous equations. Sargan became interested in the estimation of those models, and extended them to the case of autoregressive disturbances. The second of Sargan's papers on instrumental variables deals with models with autoregressive disturbances.

The contribution of Sargan to the topic of instrumental variables has been so definitive that despite the earlier work referred to above and the work by Durbin (1954), the instrumental variables method in its modern approach is inevitably linked to Sargan's name. During two decades, the interpretation of these estimators in the context of linear models as two-stage and three-stage least squares methods was the most popular one for both teaching and research purposes. However, when the development of rational expectations methods and of microeconometrics, along with the increase in computing power, had stimulated interest in non-linear models, it was realized that Sargan's strategy was still valid 
in a huge class of estimation problems. This method, called generalized method of moments in Hansen's (1982) seminal work, is based on Sargan (1958b).

His course on Econometric Theory was for a long period one of the pillars of the M.Sc. program in Econometrics at the London School of Economics. During Denis Sargan's stay with us in 1992 sponsored by the Fundación Carlos III, the graduate students of the Universidad Carlos III had the opportunity first hand to attend his course on instrumental variables.

In his interview with Peter Phillips, Sargan tells us that he already started to apply his instrumental variables method in Leeds to his model of the British economy, obtaining an estimate of the Phillips curve. These results were never published because he did not believe the ease with which a small increase in unemployment would cure inflation.

The research on instrumental variables contained in the two articles mentioned above shows the general applicability of the procedure to models that combined, on the one hand, the greatest econometric sophistication-as in the Cowles monographs - with, on the other hand, the most recent developments in time series - on stationary stochastic processes. Given that autoregressive (AR) models, moving average (MA) models, and mixed ARMA processes are all approximations to a more general stochastic process, and that using the autoregressive model was simpler, this became the obvious starting point. The introduction of autoregressive disturbances implied a non-linear estimation problem. At the same time, in these articles there is a search for an efficient estimator when there are more instruments than necessary. The second of these articles was a pioneering work, tackling estimation and inference in econometric models with many problems compounded.

In these publications on instrumental variables methods, Sargan profoundly studied the setup of the estimation problem. He derived the asymptotic properties of the estimators, solved the efficiency problem and provided an interpretation of earlier results on the maximum-likelihood estimators by Anderson and Rubin as instrumental variables estimators. Still, Sargan went further and he studied testing issues in these models. He proposed tests, at the end of the fifties, for dynamic misspecification of the models. This research would be developed further in his $1964 \mathrm{~b}$ article.

In 1958, Sargan started a long stay in the United States that would have a lasting influence on his future orientation. In his own words, in the United Kingdom in those days there was little interest in econometrics with the exception of the Department of Applied Mathematics at Cambridge. On the contrary, Minnesota, Chicago and Yale in the USA had people very interested in this discipline and he got in touch with Chipman, Fisher, and Griliches among others.

During this American period, Sargan decided to concentrate his research efforts. He abandoned mathematical economics in order to intensify his work in econometric theory and applied econometrics. At the same time he realized that the use of computers would allow the routine daily application of estimation methods that were previously infeasible. He decided to investigate the devel- 
opment of such procedures by working on algorithms that could be implemented in computer code.

A first result of this concentration of his research interest in econometrics is the article published in Econometrica in 1961, "The Maximum Likelihood Estimation of Economic Relationships with Autoregressive Residuals." In the extension of the simultaneous equation models to autoregressive disturbances we already find the idea, later fully developed in different papers, that isolating the residual dynamics will simplify the representation of the dynamics of economic variables. The article considers an open model-i.e., one with exogenous variables - and a closed model with all the variables determined inside it. These models, today known as VAR models, have become very popular in the literature after Sims' (1980) paper in Econometrica.

This research agenda on the estimation of simultaneous equations models with autoregressive disturbances would later be extended in David Hendry's doctoral thesis at the London School of Economics in 1970 and in a series of papers by Hendry (Hendry, 1971, 1976). A semiparametric approach to the estimation of simultaneous equations models with stationary disturbances was developed and implemented in Espasa's doctoral dissertation at LSE in 1975 and in the publications that emerged from it (Espasa and Sargan, 1977; Espasa, 1997).

The relationship between FIML estimators and the corresponding instrumental variables estimators was studied by Sargan in his paper "3SLS and FIML Estimates," where he showed their asymptotic equivalence. This is the last article that Sargan wrote at the University of Leeds, where he returned in 1960 after his stay in the United States.

At the beginning of the 1963-64 academic year Sargan joined the London School of Economics and was appointed professor in the following year. He would stay on at that school until his retirement in 1984 when he was appointed emeritus professor. Most of Sargan's academic life was, therefore, spent at the London School of Economics, more familiarly known as the LSE, whose prestige in the field of econometrics is in a good part a result of his work and his influence on students and colleagues.

When Sargan arrived at the LSE he met James Durbin and Bill Phillips and organized graduate courses for the M.Sc. in Mathematical Economics and Econometrics. They were joined in this effort by Terence Gorman and Frank Hahn and Meghnad Desai who joined the LSE a couple of years later. The teaching of Econometrics at the LSE was greatly expanded through its introduction in undergraduate and graduate studies, and reached a very high level in the Masters' program. This commitment to the teaching of econometrics took place at a time when econometrics was no longer a popular choice at graduate schools in the United States and even the Cowles Commission itself showed little interest in the discipline.

Embedded in the M.Sc. program in Mathematical Economics and Econometrics, Sargan organized a weekly Econometrics Seminar. Professor T.W. 
Anderson, who visited the London School of Economics during the academic year 1974-75, considered that the attending participants at that seminar formed the most active and productive group of econometricians of that time. The fame of the group in Mathematical Economics and Econometrics at the LSE has attracted, in addition to those already mentioned, people like Atkinson, Bean, Dasgupta, Desai, Goodhart, Hart, Harvey, Hendry, King, Layard, Mizon, Moore, Morishima, Nickell, Pissarides, Roberts, Robinson, Sen, Stern, Sutton, Wallis, etc. Some of them still teach and carry out research at the LSE. In 1987 this department was ranked the best of the world in Theoretical Econometrics. With Sargan's retirement, his chair was occupied by Peter Robinson, who has contributed to the maintenance of the econometric reputation of the School.

During his years at the LSE, Sargan directed more than forty doctoral theses. He also exerted such influence on his colleagues that he has motivated the development of many research traditions: "3SLS and FIML estimation" and "econometric methodology," whose formalization and extension owe much to David Hendry's intense and continuing work and which have become known as the "LSE econometric methodology," although many of its followers are no longer at the LSE or have ever been affiliated with the School. The Universidad Carlos III is honoured that, at this testimonial to Denis Sargan's scientific work, in addition to the Spanish people who were fortunate enough to have been his doctoral students, there is also a select group of his disciples from Europe and America present.

His first article published while he was at the LSE, in 1964, "Wages and Prices in the U.K.: A Study in Econometric Methodology," constitutes one of his principal papers in which he anticipated many of the developments that would take place later in the field of econometric modelling. Unfortunately, this paper appeared in volume XVI of the Colston Papers, which was not a well-known publication amongst econometricians. For that reason, the paper did not reach as wide an audience as it deserved. Nevertheless, known as the "Colston Paper," it exerted a great influence on the people close to Denis Sargan. Hendry and Wallis, two decades later, on the occasion of Sargan's sixtieth birthday, edited a volume recognizing the influence of the "Colston Paper" on econometrics. The volume contained nine chapters, by the same number of authors, in which different themes present in the 1964 paper (also reproduced in the volume) are developed.

The "Colston Paper" contains important contributions to the estimation of dynamic models, conditions for convergence of iterative procedures, hypothesis testing methods on autoregressive disturbances, and comparisons between linear and log-linear models. It is worth noting that this work extends and formalizes tests on misspecification of dynamic models, introduces error correction mechanisms, and develops a modelling strategy for a specific application. This application was performed on the subject of wages and prices, which Sargan had chosen as a field in which to carry out his applied work, given his lack of satisfaction with the earlier results on the Phillips curve. 
The error correction mechanism consists of adding to the dynamic modelling of variables which exhibit trend a combination of their levels which is stationary. The introduction of this type of mechanism in econometric models corresponds with Sargan's interest and ability in incorporating economic theory in econometric methodology developments.

His theoretical and empirical work on dynamic modelling constitutes one of his principal contributions to econometrics. It was developed in a series of papers during the seventies and the eighties, some of them not then published but still very influential, in which he continued the study of issues that already appeared in the "Colston Paper." Among them, it is worth mentioning those dealing with misspecification and inference. In these papers, following the "Colston Paper" tradition, he proposed in a linear model context to operate from the general to the specific, which had been a very unusual econometric practice for many years. Precisely this principle is one of the main constituents of the "Methodology of the LSE." In this general-to-specific strategy which appears in Sargan's work, the COMFAC procedure for testing common dynamic factors stands out. With this procedure, one tries to determine a dynamic relationship between economic variables which is not contaminated by the dynamic structure of the residuals. In later work by Hendry and Mizon (see Hendry and Mizon, 1978; Mizon and Hendry, 1980) important applications of this procedure are developed. A related anecdote (Hendry, 1993) shows the enormous intellectual capacity and genial manner of Denis Sargan the scientist. In 1975 David Hendry was delivering a seminar at the LSE in which he was trying to generalize the test formalized in the "Colston Paper" about the validity of a first-order autoregressive error term versus a structural formulation of one more lag. At the end of the presentation, Sargan told Hendry that he didn't understand the paper and asked him to deliver it again a week after. So it happened, and in this second session Sargan suddenly pointed out that the problem was now clear, and that he had realized that the difficulties consisted of testing from the specific to the general and not vice versa. In a few weeks he had implemented the common factors approach.

Sargan's contribution to research on dynamic models has been very broad, covering, in addition to the areas already mentioned, unit roots, missing observations, continuous time models, semiparametric estimation by spectral methods, panel data models, and rational expectations models. One of his works on this subject is in the Working Paper series of this university and is published in the Spanish journal Revista Española de Economía (1993). Especially relevant is his pioneering work on testing for unit roots in the residuals of regression models and about the properties of estimators in over differenced regression models. This line of research resulted in two publications in Econometrica with A. Bhargava in 1983 and is particularly significant because of the important development that cointegration theory and models with integrated series have experienced in the eighties.

Sargan's contributions to the study of finite sample distributions of econometric estimators and test statistics merit a special mention. This is because 
these contributions have been very innovative, originating completely new areas of research in econometrics. Sargan's work in this area responds to a fundamental concern for improving significance tests and in learning about the properties of estimators. For this reason, his work has three outstanding characteristics. In the first place, he did not concentrate on a particular type of technique, but instead he approached the problem from many different angles: Edgeworth expansions, exact distributions, Monte Carlo simulation, criteria about the existence of moments or the determination of the order of magnitude for the difference between asymptotically equivalent estimators. In the second place, his objective was to provide solutions to problems of real interest: systems of autoregressive simultaneous equations which interested him from an applied point of view. Finally, he paid a lot of attention to practical computational problems and to the development of algorithms that allow for the implementation of the theory in practice.

During the sixties, as a result of his concern that all econometric theory was based on asymptotics, except for the linear regression model, Sargan became interested in Edgeworth approximations to the distributions of instrumental variables estimators. This research resulted in an article published with Mikhail in 1971. This article was followed by others in 1975 on the approximations of $t$-statistics, and in 1980 about the approximation of statistics with an asymptotic $\chi^{2}$ distribution. Nevertheless, the most outstanding result of this research is his work published in 1976 entitled "Econometric Estimators and the Edgeworth Approximations." In this work it is shown how it is possible to obtain an Edgeworth expansion for practically any statistic with an asymptotic normal distribution and defined as a function of the second moments of data from a stationary process. Sargan's theorem combines a multivariate Edgeworth approximation of the second moments of the data with a Taylor expansion of the statistic. Besides, this work contains several appendices with an unusual wealth of diverse material which forms the basis for later developments by Sargan's disciples. Particularly important are his results about exact distributions of estimators in simultaneous equation models. Also, the results about control variates in Monte Carlo studies, along with a proposal for the simulation of tail probabilities in hypothesis testing. The development of expansions for statistics defined as functions of the second moments of the data of a dynamic model, but with a $\chi^{2}$ distribution, is treated in Mauleón's 1983 LSE doctoral dissertation. In many of the works of Sargan and Tse the quality of the Edgeworth approximations is evaluated for numerous statistics. In later work by Arellano and Sargan, published in 1990, alternative expansions based on the Imhof distribution are developed. Their behaviour may be expected to be superior to that of Edgeworth approximations in the case of dynamic models with roots close to unity.

In parallel to his work on Edgeworth expansion, Sargan obtained conditions for the existence of moments of econometric estimators. Specifically, he established results about the existence of moments of FIML and 3SLS estimators in 
the reduced and structural forms. The results about the nonexistence of moments for FIML estimators of the structural coefficients were never published until they appeared in the volumes edited by Maasoumi, while those concerning 3SLS were published in 1978. Closely related to this subject, Sargan studied the validity of the Nagar expansions for moment estimators in a 1974 article, and he provided a general theorem about the validity of Edgeworth expansions in a paper with Satchell published in 1986.

Sargan has always had a big passion for econometrics and he has enjoyed long technical discussions with his colleagues, but these discussions have often been diverted if the subject of gardening was mentioned. For Sargan, econometrics has never been able to compete with gardening and for Denis the most important things have always been rooted in earth.

In 1962 Sargan was elected fellow of the Econometric Society and in 1980 was appointed president of this society. In his presidential address at the World Congress that year, Sargan presented his paper "Identification and Lack of Identification," in which he carried out a general analysis of the subject and presented identification as a property of an econometric model and not as a characteristic of the real world. His research on identification dates from 1972, in a lecture to the Royal Statistical Society. This paper, very well known for years among econometricians, was never published and is one of the works edited by Maasoumi. In subsequent papers Sargan develops the results of his presidential address.

A characteristic of Sargan's work is the mathematical complexity of his papers. Nevertheless, as Maasoumi points out, this complexity is necessary to formulate the problems and to incorporate the conditions which are important in practice, and to produce general solutions to them. The careful reader of Sargan's papers soon realizes the generality of the expositions and of the given solutions, and independent of the knowledge gained on the subject itself, the readers will value the wealth of the analytic tools which have allowed such a general treatment and try to include them as devices in their own research.

Sargan's mastery of mathematics can be illustrated by an anecdote told by his wife, Mary. One night she arrived home around midnight, to find Denis sitting on the floor of their sitting room in front of the fire solving equations - in fact Edgeworth expansions for his famous paper-with the T.V. blaring, their young children running around and jumping on top of him, and with the radio on in another room. Astonishingly, the equations seem to have been correct!

Modern Econometrics as a field has been developed in close connection with the Econometric Society and its journal Econometrica, whose first issue was published in 1933. In it, Frisch, the president of the society at that moment, while explaining his view of econometrics pointed out that each one of the "three view-points, statistics, economic theory and mathematics, is a necessary, but not by itself sufficient condition for a real understanding of the quantitative relations in modern economic life. It is the unification of all three that is powerful. And it is this unification that constitutes econometrics." This unification, 
as has been emphasized by Hendry and Wallis, defines Sargan's work that, one could add, has been well ahead of its time.

The members of the Universidad Carlos III of Madrid are highly honored with the presence today of Denis Sargan. The gesture with which he distinguishes us today is the best stimulus that staff and students could receive in order to fulfil our job of constructing this young university. The recognition and immense respect for the work of Professor Sargan and the wish that it be taken as an example to follow are what have induced the Departments of Economics and Statistics and Econometrics to propose him for the degree of Doctor Honoris Causa of this institution.

Denis Sargan, many thanks for your magistery.

\section{REFERENCES}

Anderson, T.W. \& H. Rubin (1949) Estimation of the parameters of a single equation in a complete system of stochastic equations. Annals of Mathematical Statistics 20, 44-63.

Anderson, T.W. \& H. Rubin (1950) The asymptotic properties of estimators of estimates of the parameters of a single equation in a complete system of stochastic equations. Annals of Mathematical Statistics 21, 570-582.

Durbin, J. (1954) Errors in variables. Review of the Institute of International Statistics 22, 23-31.

Espasa, A. (1977) El problema de la desestacionalización de series económicas: métodos utilizados y su interpretación. Boletín de Estudios Económicos 32, 461-478.

Espasa, A. \& J.D. Sargan (1977) The spectral estimation of simultaneous equation systems with lagged endogenous variables. International Economic Review 18, 583-605. Later published in J.D. Sargan, Contributions to Economics, Vol. 2, E. Maasoumi (ed.), (Cambridge: Cambridge University Press, 1988).

Geary, R.C. (1949) Determination of linear relations between systematic parts of variables with errors of observations, the variances of which are unknown. Econometrica 17, 30-58.

Hansen, L.P. (1982) Large sample properties of generalized method of moments estimators. Econometrica 50, 1029-1054.

Hendry, D.F. (1971) Maximum likelihood estimation of systems of simultaneous regressions equations with errors generated by a vector autorregresive process. International Economic Review $12,257-272$.

Hendry, D.F. (1976) The structure of simultaneous equation estimators. Journal of Econometrics 4, 51-88.

Hendry, D.F. \& G.E. Mizon (1978) Serial correlation as a convenient simplification, not a nuisance: A comment on a study of the demand for money by the Bank of England. Economic Journal 88, 549-563.

Hendry, D.F. \& K.F. Wallis (eds.) (1984) Introduction by the editors. In D.F. Hendry \& K.F. Wallis (eds.), Econometrics and Quantitative Economics, pp. 1-12. Oxford: Basil Blackwell.

Hood, W.C. \& T.C. Koopmans (eds.) (1953) Studies in Econometrics Method. Cowles Commission Monograph 14. New York: Wiley.

Koopmans, T.C. (ed.) (1950) Statistical Inference in Dynamic Economic Models. Cowles Commission Monograph 10. New York: Wiley.

Maasoumi, E. (1988a) Denis Sargan and his seminal contributions to economic and econometric theory. Introduction to J.D. Sargan, Contributions to Econometrics, E. Maasoumi (ed.), vol. 6. Cambridge: Cambridge University Press.

Maasoumi, E. (1998b) Contributions of Denis Sargan to the theory of finite sample distributions and dynamic econometric models. Introduction to J.D. Sargan, Contributions to Econometrics, E. Maasoumi (ed.), vol. 2. Cambridge: Cambridge University Press. 
Mauleón, I. (1983) Approximations to the finite sample distribution of econometric chi-squared criteria, Ph.D. dissertation, London School of Economics.

Mison, G.E. \& D.F. Hendry (1980) An empirical application and Monte Carlo analysis of tests of dynamic specification. Review of Economic Studies 49, 21-45.

Phillips, P. (1985) ET Interview: Professor J.D. Sargan. Economic Theory 1, 119-139.

Reiersol, O. (1941) Confluence analysis by means of lag moments and other methods of confluence analysis. Econometrica 9, 1-24.

Reiersol, O. (1945) Confluence analysis by means of instrumental sets of variables. Arkiv for Matematik, Astronomi, och Fysik, Almquist and Wicksells Boktryckeri-AB, Uppsala, 1-119.

Sims, C.A. (1980) Macroeconomics and reality. Econometrica 48, 1-48. Later published as chapter 8 in C.W.J. Granger (ed.) (1990), Modelling Economic Time Series, pp. 137-189. Oxford: Clarendon Press.

Wright, P. (1928) Appendix B. In P. Wright (ed.), The tariff on animal and vegetable oils. MacMillan.

\section{PUBLICATIONS BY J. DENIS SARGAN}

Metroeconomica (1951) A new approach to the general distribution problem, 3, 108-116.

Yorkshire Bulletin of Economic and Social Research (1952) An illustration of duopoly, 4, 133-145. Yorkshire Bulletin (1953a) Subjective probability and the economist, 5, 53-64.

Journal of the Royal Statistics Society (1953b) An approximate treatment of the properties of correlogram and periodogram, 8, 140-152.

Econometrica (1955) The period of production, 23, 151-165.

Econometrica (1956) A note on Mr. Blyth's article, 24, 480-481.

Econometrica (1957a) The distribution of wealth, 25, 568-590.

Bulletin of Oxford Institute of Statistics (1957b) The dangers of oversimplification, 19, 171-178.

Econometrica (1958a) The instability of the Leontief dynamic model, 26, 381-392.

Econometrica (1958b) The estimation of economic relationships using instrumental variables, B, 21, 91-105.

Yorkshire Bulletin (1958c) Mrs. Robinson's warranted rate of growth, 10, 35-40.

Journal of the Royal Statistical Society, Series B (1959a) The estimation of relationships with autocorrelated residuals by the use of instrumental variables, 21, 91-105.

Econometrica (1959b) Linear models for the frequency distributions of economic variables, Abstract, 27, 315-316.

Econometrica (1961a) The maximum likelihood estimation of economic relationships with autoregressive residuals, 29, 414-426.

Econometrica (1961b) Lags and the stability of dynamic systems: A reply, 29, 670-673.

Econometrica (1964a) 3SLS and FIML estimates, 32, 77-81.

"Colston Paper" (1964b) Wages and prices in the UK: A study in econometric methodology. In P.E.

Hart, G. Mills, \& J.K. Whitaker (eds.), Econometric Analysis for National Economic Planning, pp. 25-54. London: Butterworth Co., Ltd. Reprinted in D.F. Hendry \& K.F. Wallis (eds.), Econometrics and Quantitative Economics (Oxford: Basil Blackwell, 1984).

Econometrica (1964c) An approximate distribution of the two-stage least squares estimators, Abstract, 32, 660.

(1971a) Production functions, with P.R.G. Layard, M.E. Ager, \& D.J. Jones. In Qualified Manpower and Economic Performance, part 5: An Inter-plant Study in the Electrical Engineering Industry, pp. 143-204. London: Allen Lane, the Penguin Press.

Econometrica (1971b) A general approximation to the distribution of instrumental variable estimates, with W.M. Mikhail, 39, 131-169.

(1971c) A study of wages and prices in the UK, 1949-1968. In H.G. Johnson \& A.R. Nobay (eds.), The Current Inflation, pp. 52-71. London: Macmillan.

Econometrica (1974a) The validity of Nagar's expansion for the moments of econometric estimates, 42, 169-176. 
Journal of the Royal Statistical Society, Series B (1974b) Some discrete approximations to continuous time stochastic models, 36, 74-90.

International Economic Review (1974c) Missing data in an autoregressive model, with E.G. Drettakis, $15,39-58$.

International Economic Review (1975a) Asymptotic theory and large models, 16, 75-91.

Econometrica (1975b) Gram-Charlier approximations applied to t-ratios of k-class estimators, 43, 327-346.

Econometrica (1976a) Econometric estimators and the Edgeworth approximations, 44, 41-48.

(1976b) Some discrete approximations to continuous time stochastic models. In A.R. Bergstrom (ed.), Statistical Inference in Continuous Time Economic Models. Amsterdam: North-Holland. This is an expanded version of Sargan (1974b).

International Economic Review (1977) The spectral estimation of sets of simultaneous equations with lagged endogenous variables, with A. Espasa, 18, 583-605.

Econometrica (1978) The existence of moments of 3SLS estimators, 46, 1329-1350.

Review of Economic Studies (1980a) The consumer price equation in the post war British economy: An exercise in equation specification testing, 47, 113-135.

Review of Economic Studies (1980b) A model of wage-price inflation, 47, 97-112.

Econometrica (1980c) Some tests of dynamic specification for a single equation, 48, 879-897.

Econometrica (1980d) Some approximations to the distributions of econometric criteria which are asymptotically distributed as chi-squared, 48, 1107-1138.

(1981) Edgeworth approximations to the distributions of various test statistics, with Y.K. Tse. In E.G. Charatsis, Proceedings of the 1979 European Society Meetings, pp. 281-295. Amsterdam: North-Holland.

Advances in Econometrics (1982) On Monte Carlo estimate of moments that are infinite, 1, 267-299.

Econometrica (1983a) Identification and lack of identification, 51, 1605-1633.

(1983b) Identification in models with autoregressive errors. In S. Karlin, T. Amemiya, \& L.A. Goodman (eds.), Studies in Econometrics, Time Series, and Multivariate Statistics in Honor of T.W. Anderson, pp. 169-205. New York: Academic Press.

Econometrica (1983c) A generalization of the Durbin significance test and its application to dynamic specification, with F. Mehta, 51, 1551-1567.

Econometrica (1983d) Testing residuals from least squares regression for being generated by the Gaussian random walk, with A. Bhargava, 51, 153-174.

Econometrica (1983e) Maximum likelihood estimation of regression models with first order moving average errors when the root lies on the unit circle, with A. Bhargava, 51, 799-820.

Econometrica (1983f) Estimating dynamic random effect models from panel data covering short time periods, with A. Bhargava, 51, 1635-1659.

(1984) Dynamic specification, with D.F. Hendry \& A.R. Pagan. In Handbook of Econometrics, vol. II. Amsterdam: North-Holland.

Econometrica (1986) A theory of validity for Edgeworth expansions, with S.E. Satchell, 54, 189-213.

Review of Economic Studies (1990) Imhof approximations to econometric estimators, with M. Arellano, 57, 627-646.

Revista Española de Economía (1993) Estimation methods for simple rational expectations models, 10(1), 5-18. 